\title{
Hypertension in children with chronic kidney disease: pathophysiology and management
}

\author{
Charlotte Hadtstein • Franz Schaefer
}

Received: 9 August 2007 /Revised: 29 August 2007 / Accepted: 11 September 2007 / Published online: 8 November 2007

(C) IPNA 2007

\begin{abstract}
Arterial hypertension is very common in children with all stages of chronic kidney disease (CKD). While fluid overload and activation of the renin-angiotensin system have long been recognized as crucial pathophysiological pathways, sympathetic hyperactivation, endothelial dysfunction and chronic hyperparathyroidism have more recently been identified as important factors contributing to CKD-associated hypertension. Moreover, several drugs commonly administered in CKD, such as erythropoietin, glucocorticoids and cyclosporine $\mathrm{A}$, independently raise blood pressure in a dose-dependent fashion. Because of the deleterious consequences of hypertension on the progression of renal disease and cardiovascular outcomes, an active screening approach should be adapted in patients with all stages of CKD. Before one starts antihypertensive treatment, non-pharmacological options should be explored. In hemodialysis patients a low salt diet, low dialysate sodium and stricter dialysis towards dry weight can often achieve adequate blood pressure control. Angiotensin-converting enzyme (ACE) inhibitors and angiotensin receptor blockers are first-line therapy for patients with proteinuria, due to their additional anti-proteinuric properties. Diuretics are a useful alternative for non-proteinuric patients or as an addon to renin-angiotensin system blockade. Multiple drug therapy is often needed to maintain blood pressure below the 90th percentile target, but adequate blood pressure control is essential for better renal and cardiovascular longterm outcomes.
\end{abstract}

C. Hadtstein $\cdot$ F. Schaefer $(\bowtie)$

Division of Pediatric Nephrology,

Center for Pediatric and Adolescent Medicine,

University Hospital of Heidelberg,

Im Neuenheimer Feld 151,

69120 Heidelberg, Germany

e-mail: franz.schaefer@med.uni-heidelberg.de
Keywords Hypertension · Children · Chronic kidney disease $\cdot$ Pathophysiology · Antihypertension therapy Life-style changes

\section{Introduction}

Hypertension is one of the most common sequelae of chronic kidney disease (CKD) in children [1]. CKDassociated hypertension develops by a large variety of pathophysiological mechanisms. Blood pressure is one of the most critical determinants of the progression rate of renal failure in children [2, 3], and cardiovascular mortality in childhood onset renal failure [4]. Therefore, good antihypertensive management can substantially contribute to better renal and patient survival of adults with childhoodonset CKD.

As in many other complications of chronic renal failure, patients often do not report symptoms of hypertension, so an active screening approach is needed to prevent endorgan damage.

This article aims to give a short overview of the different pathophysiological pathways that lead to hypertension in CKD in order to explain how these can be targeted by different therapeutic approaches.

\section{Pathophysiology of hypertension in CKD}

Fundamentally, increased blood pressure is caused by an increase in cardiac output and/or of total peripheral resistance. Both can be altered by a plethora of different mechanisms in uremia and renal failure. Additionally, children with certain underlying diseases, e.g. glomerulopathies and polycystic kidney disease, are especially susceptible to hypertension [3, 
5]. Figure 1 gives an overview of the most important pathways involved.

Activation of the renin-angiotensin-aldosterone system plays a pivotal role in renal hypertension. While plasma renin activity is typically found to be markedly elevated only in patients with renal artery stenosis, many patients with CKD have 'inappropriately normal' renin levels (i.e. lower levels would be expected, considering their degree of hypertension and fluid overload [6, 7]). Hyper-reninemia occurs probably due to renin secretion in poorly perfused areas such as cysts and scars or after microangiopathic damage or tubulo-interstitial inflammation $[8,9]$ and leads to angiotensin II-mediated vasoconstriction as well as aldosterone-mediated salt retention, thus increasing both total peripheral resistance and blood volume. Additional delayed effects of a high angiotensin II tone include inflammation, cardiac hypertrophy and endothelial cell damage, mesangial cell proliferation and fibrosis [10], which contribute further to hypertension and end-organ damage.

Sodium retention and consequent fluid overload have long been recognized as causes of hypertension in CKD. Hypertensive children on dialysis have lower residual urine output than their normotensive peers have [5]. While interdialytic weight gain is correlated with the inter-dialytic increase in ambulatory blood pressure, the correlation is rather weak (in children $r=0.41$ [11]). This may be due to delayed effects [12] but also points to important volumeindependent factors regulating blood pressure (BP) in patients on hemodialysis. This is also illustrated by the fact that nephrectomy in children on dialysis lowers mean blood pressure, despite causing anuria [13]. It has been proposed that fluid overload leads to hypertension only in those patients in whom peripheral resistance fails simultaneously to fall, i.e. when additional factors interfere with vascular autoregulation [14].

A growing body of evidence suggests that increased activity of the sympathetic nervous system (SNS) is an

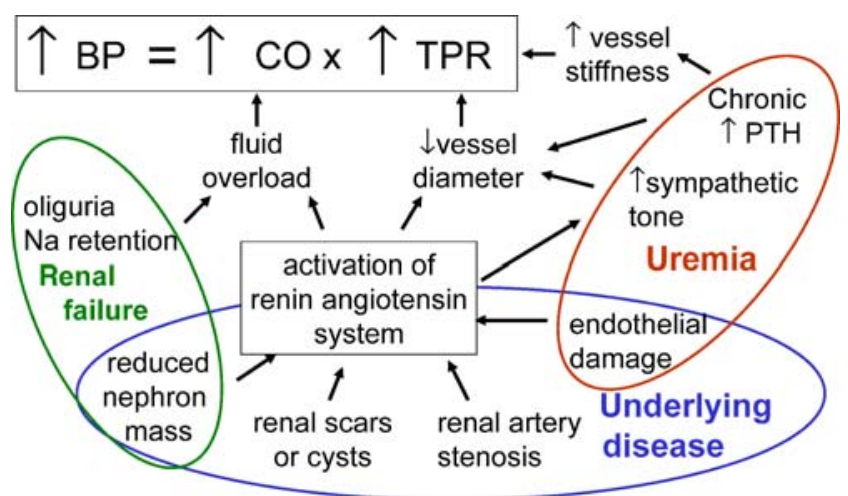

Fig. 1 Interplay of different factors in the generation of hypertension in chronic kidney disease ( $B P$ blood pressure, $C O$ cardiac output, TPR total peripheral resistance, $P T H$ parathyroid hormone, $N a$ sodium) important volume-independent cause of hypertension. Campese et al. demonstrated that renal denervation improves both hypertension and increased sympathetic activity caused by phenol injection into rat kidneys [15]. Muscle sympathetic nerve activity is also elevated in hypertensive patients with chronic renal failure [16]. The underlying mechanisms of this phenomenon are, as yet, unclear and may include afferent signals from the failing kidney as well as dopaminergic abnormalities and the accumulation of leptin in CKD [17, 18]. Interestingly, not only beta blockade but also angiotensin-converting enzyme (ACE) inhibition can reduce the sympathetic hyperactivation of CKD [16, 19]. However, as sympathetic hyperactivity is also a feature of renovascular hypertension [20], essential hypertension and hypertensive patients with polycystic kidney disease [13], it appears that sympathetic activation also occurs independently of renal function. The most established cause for sympathetic over-activation is renal ischemia caused by renal artery stenosis [20,21], but renal cysts might also cause local renal ischemia.

While children with end-stage renal disease (ESRD) usually have normal plasma noradrenaline and adrenalin concentrations, hemodialysis per se leads to substantial increase in both plasma renin activity and catecholamines, which can contribute to hypertension [22].

Recent experimental evidence suggests that renalase - an amine oxidase specifically expressed by the kidneylowers blood pressure and heart rate. Its activity is markedly reduced in patients with ESRD [23]. However, whether the cardiovascular effects of this enzyme are really due to its catecholamine-metabolizing activity is still controversial [24].

There has been debate about the role of nitric oxide (NO) in mediating endothelial cell damage and hypertension in CKD. Newer studies have demonstrated that, in uremic patients, reduced NO stimulation leads to reduced agonistinduced endothelium-dependent vasodilatation, whereas other vasodilatory pathways are not affected. Renal failure leads to the accumulation of endogenous NO synthase inhibitors such as asymmetric dimethyl-L-arginine (ADMA), which appears to be due to increased generation and decreased metabolism rather than decreased clearance [25]. ADMA independently predicts overall mortality and cardiovascular events in patients with ESRD [26], as well as progression of CKD [27]. While ADMA is related to blood pressure in animal models of $\mathrm{CKD}$, clinical studies have not found differences in blood pressure [25].

Endothelial NO synthase is also suppressed by hyperparathyroidism in rats with CKD [28]. In contrast to ADMA levels, those of serum parathyroid hormone (PTH) correlate highly with blood pressure in patients with CKD [29]. Whereas acute infusion of PTH has a hypotensive effect, chronic hyperparathyroidism leads to accumulation 
of calcium inside vascular smooth muscle cells, enhancing their sensitivity to calcium and norepinephrine [30, 31]. This effect can be blocked by calcium channel antagonists.

A number of drugs commonly administered in CKD can cause iatrogenic hypertension. For example, erythropoietin (EPO) causes blood pressure elevation over several weeks. This may be via arterial wall remodeling, causing increased vascular resistance [32]. Vaziri et al. have proposed that EPO acts directly on voltage-independent calcium channels in smooth muscle cells, leading to a decreased sensitivity to the vasodilatory action of nitric oxide [33]. The resulting possibility of calcium channel antagonists as 'specific' therapy for EPO-induced hypertension has been successfully tested in rats [34].

Glucocorticoids lead to fluid retention by their mineralocorticoid effect. Cyclosporine A causes vasoconstriction of glomerular afferent arterioles and hyperplasia of the juxtaglomerular apparatus, with subsequent increased release of renin and angiotensin II [35]. Increased circulating catecholamines and endothelin-1 precursors, and increased renal sodium absorption via the $\mathrm{Na}-\mathrm{K}-2 \mathrm{Cl}$ co-transporter in the loop of Henle [36], have also been demonstrated after cyclosporine A treatment. Tacrolimus appears to be less pro-hypertensive than cyclosporine in children after renal transplantation [37], but, for other reasons, it is less commonly used prior to transplantation [38].

Treatment with growth hormone leads to water and sodium retention by the distal nephron [39], mediated by increased intra-renal insulin-like growth factor (IGF)-1. However, growth hormone $(\mathrm{GH})$ does not appear to increase blood pressure in children with CKD or Turner syndrome, despite both groups being prone to hypertension $[40,41]$.

\section{Management}

Owing to the lack of acute symptoms and to the serious long-term consequences of hypertension, an active screening approach is necessary to detect elevated blood pressures early and to prevent end-organ damage [42]. In contrast to other complications of $\mathrm{CKD}$, which become prevalent only in later stages of CKD, hypertension is already very common in CKD stage 1, with over $63 \%$ of children affected. In CKD stages 4 and 5 the incidence increases further to $80 \%$ [1]. More than $50 \%$ of children with ESRD have uncontrolled hypertension, despite widespread use of antihypertensive drugs [5, 43]. The frequency of blood pressure measurement during screening and during therapy should be appropriate to the patient's risk of developing uncontrolled hypertension. A routine for this is suggested in the flow chart in Fig. 2. In general, we would consider all children with CKD to be at least at intermediate risk, and, therefore, we recommend 3-monthly clinic blood pressure (CBP) measurements; children with ESRD, multiple prohypertensive medications or confirmed hypertension should be considered as at high risk. In our experience $24 \mathrm{~h}$ ambulatory blood pressure measurement (ABPM) is a very valuable tool and should be performed annually in high-risk populations such as renal transplant recipients or those with rapidly progressive renal disease. ABPM is also useful to exclude white-coat hypertension, which is a problem even in children under long-term medical care [44]. While there are equivocal results about the long-term consequences of white-coat hypertension, end-organ damage could be clearly demonstrated in children with masked hypertension, i.e. elevated ABPM but normal CBP [45], underlining the usefulness of this method.

Whichever method is used, techniques should be in accordance with international consensus statements, and the appropriate pediatric reference ranges are very important. These are now available for clinic [46, 47], ambulatory [48] and home blood pressure measurements [49]. The diagnosis of hypertension should be based on at least three clinic blood pressure measurements above the 95th percentile [46]. As white-coat hypertension is very common, and the effects of thorough investigation and treatment can be farreaching, we feel ABPM is advisable in nearly all newly diagnosed hypertensive children. In countries where health care providers do not cover the cost of ABPM, home blood pressure measurements may be helpful in confirming the diagnosis, but they do not pick up the nocturnal blood pressure dynamics [44].

Once hypertension has been confirmed, good management should not focus only on pharmacological therapy, but also on detection and treatment of end-organ damage and, where appropriate, improvement of the dialysis regime and consideration of therapeutic life-style changes.

Echocardiography and ophthalmological examination are the most important assessments of end-organ damage in hypertensive children. Left ventricular hypertrophy (LVH) is common in children with CKD, even during antihypertensive therapy [50]. LVH in patients with normal clinic blood pressure may indicate masked hypertension in untreated children [45] or insufficient efficacy of antihypertensive drug therapy in treated children (e.g. insufficient dose, non-compliance, or short duration of action of selected antihypertensive drugs). Echocardiography and ophthalmological evaluation should be repeated at regular intervals in children with initial signs of end-organ damage [46]. From personal experience we would also recommend follow-up examination in children with persistent hypertension or in those at high risk (e.g. ESRD). Additional assessments of end-organ damage include measurement of carotid intima media thickness and of pulse wave velocity, which reflect functional alterations of arterial wall properties caused 
Fig. 2 Flow diagram for the choice of method to measure blood pressure during screening, follow up and treatment $(C B P$ clinic blood pressure $A B P M$ $24 \mathrm{~h}$ ambulatory blood pressure monitoring, $H B P$ home blood pressure measurement $B P$ blood pressure, $B M I$ body mass index)

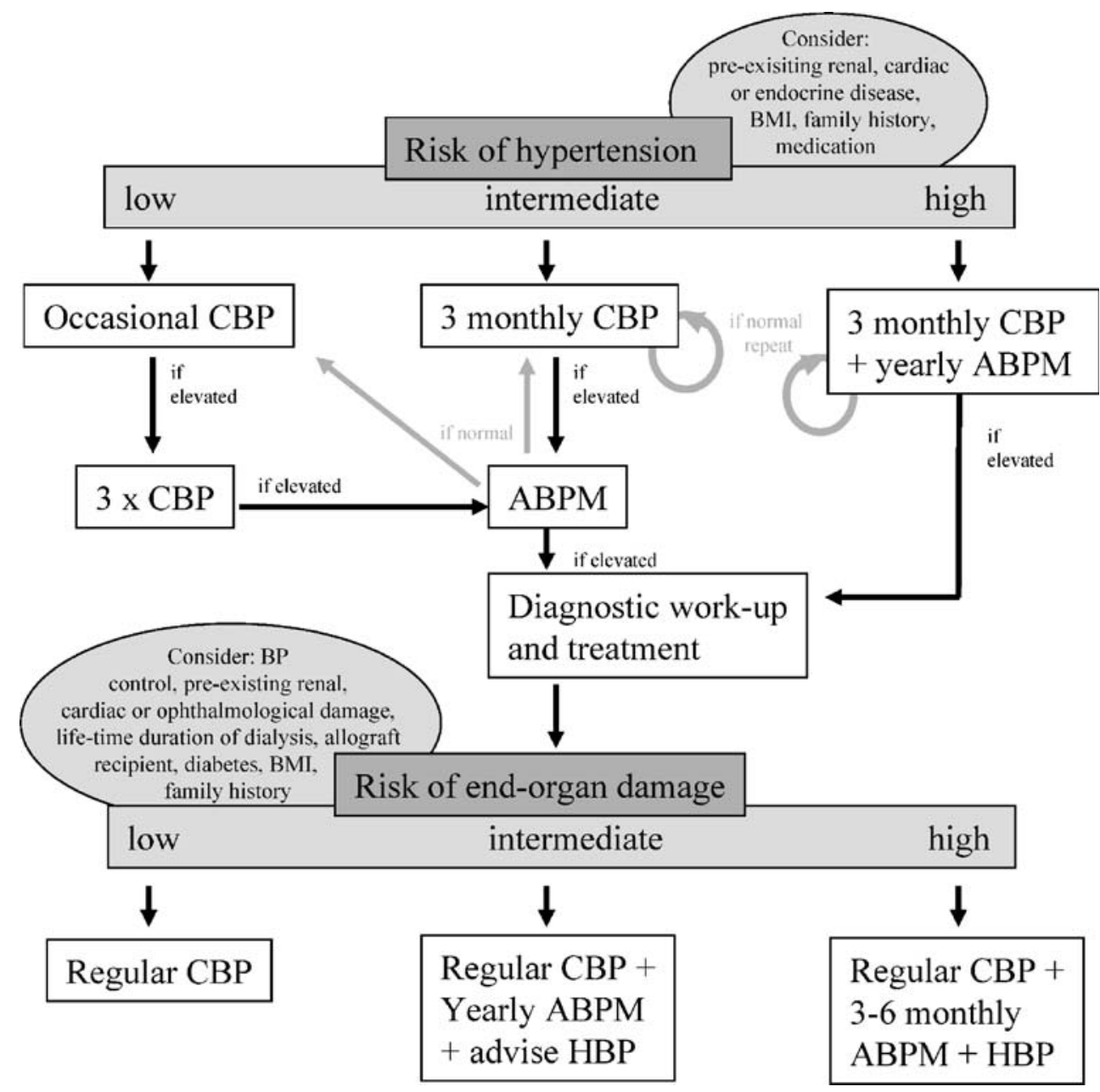

by hypertension and other factors such as hyperparathyroidism [51]. These investigations are still mainly used for research purposes, but clinical use has been facilitated by the recent provision of pediatric reference ranges [52].

In hypertensive patients who are undergoing renal replacement therapy, improvement of the dialysis prescription should be the primary therapeutic approach to hypertension, before pharmacological treatment is started. Extracellular volume overload can be efficiently reduced by adequately long dialysis times. Even though the reduction of fluid overload may take several weeks to translate into normalized blood pressure, drug-free control of hypertension is possible in many, if not most, hemodialysis patients [12]. A number of studies have shown improved BP control with short daily, long intermittent or nocturnal hemodialysis [53]. While conventional dialysis schedules can also improve control of hypertension by targeting dry weight more aggressively [54], this tends to be tolerated less well, with more intra-dialytic hypotensive episodes. Lower concentrations of dialysate sodium also produce a moderate fall in blood pressure on a population level, with best results in patients with previously high blood pressure [55].
In addition to intensified dialysis, dietary sodium restriction is a useful adjunct to intensified dialysis in avoiding sodium overload, and it reduces intra-dialytic hypotensive episodes. Indeed, some authors find dietary sodium restriction plus low sodium dialysate to be equally effective as time-intensified dialysis, and they maintain that with good dietary advice a low salt diet need not be unpalatable [56]. However, restriction of fluid and salt intake requires considerable patient motivation, which is often a problem in the adolescent population.

Therapeutic life-style changes can be effective in lowering blood pressure if obesity contributes to the patient's hypertension. Obesity in children with CKD is uncommon and usually associated with steroid treatment; however, it is seen more commonly in populations with a higher background risk of obesity [3]. While weight loss can be effective in reducing blood pressure in overweight children with normal renal function [57], unfortunately, there are no controlled studies of life-style interventions in children with CKD. In our experience calorie-reduced diets are rarely effective in this population, probably due to the multifactorial etiology of hypertension in renal disease. 
Also, the recommended intake of fresh fruit and vegetables may be hard to achieve if a potassium- and phosphatereduced diet is also necessary. Interestingly, weight loss improves salt-induced increases in blood pressure in obese children [58]; therefore, combined calorie- and sodiumreduced diets may be particularly effective in obese CKD children who are salt retainers.

Pharmacological treatment remains the mainstay of antihypertensive management in all stages of CKD. In approximately $75 \%$ of children with CKD stages $2-4$, blood pressure control below the 95th percentile can be achieved by antihypertensive monotherapy, but $50-60 \%$ of children need more than one drug if intensified BP control $(<50$ th percentile) is targeted [Effect of Strict Blood Pressure Control and ACE Inhibition on Progression of CRF in Pediatric Patients (ESCAPE) trial, unpublished results]. In children with ESRD adequate control is much harder to achieve: a review of the North American Pediatric Renal Transplant Cooperative study (NAPRTCS) database also showed that over $50 \%$ of children on dialysis have uncontrolled hypertension [43], and a Polish nationwide survey found that in only $57 \%$ of children with ESRD was hypertension adequately controlled, despite the use of multiple drug therapy in $65 \%$ [5].

Even though multiple drug therapy is often required, it is advisable to start with a single drug at a low dose and to titrate upward until blood pressure is controlled [46]. Exceptions are hypertensive emergencies, such as hypertensive encephalopathy, when intravenous (i.v.) treatment should be started promptly.

ACE inhibitors and angiotensin II type 1 receptor blockers (ARBs) are the most useful drugs, as they are not only antihypertensive but also slow down the progression of renal failure more efficiently than do other antihypertensive treatments [59]. Surveys among pediatric nephrologists from both sides of the Atlantic show that ACE inhibitors are increasingly popular and are now the most commonly used drugs for pediatric hypertension [60, 61]. The renoprotective effect of renin-angiotensin system (RAS) blockade is due to a combination of reduced proteinuria, lower intra-glomerular pressure through selective dilatation of the glomerular efferent arteriole, and antiinflammatory and anti-fibrotic effects [10]. Additionally, RAS inhibition reduces the sympathetic hyperactivity seen in CKD [16].

There is convincing evidence from studies of adults that all proteinuric patients should receive renin-angiotensin system blockade, even if they do not have hypertension [42]. Major side effects are a moderate increase of potassium and creatinine; these should be monitored more closely with declining renal function. Sexually active adolescent girls must use contraception. ACE inhibitorinduced cough appears to be less common in children than in adults [62]. There is no clear evidence suggesting clinical superiority of ARBs over ACE inhibitors [63], and a number of drugs in both classes are labeled for children. Food and Drug Administration (FDA) approval for children under 6 years old is expected soon for a number of ARBs.

Combination therapy with an ACE inhibitor and an ARB should be considered for patients who continue to show proteinuria while undergoing monotherapy, since it is effective in further reducing proteinuria (and progression of CKD) in adults $[63,64]$. Experience in children is positive but very limited [65-68], and the increased risk of hyperkalemia and renal failure should be realized [69]. Therefore, for improved control of hypertension without proteinuria, the combination of single RAS blockade with a diuretic is preferable. The use of fixed-dose combinations of RAS antagonists with a thiazide diuretic may be an option in adolescents where compliance is an issue, but less so in younger children where frequent dose adjustments are required [46].

From trials in hypertensive patients without renal disease it appears that the blood pressure lowering effect, per se, is relevant for cardiovascular risk protection, without any class-specific benefits. Therefore, in essential hypertension, the choice of agents should be guided by the matching of the side effects profile of the individual drugs to the patientspecific risk factor profile [47]. In patients with CKD, meta-analyses of adult trials demonstrated superior renoprotection by ACE inhibitors, even after adjustment for blood pressure and urine protein excretion [70]. There is no conclusive evidence as to whether the inhibition of the renin-angiotensin system is superior to other antihypertensives in non-proteinuric CKD patients $[59,71,72]$. Recommendations for adults prefer to err on the side of caution and suggest a low threshold for considering CKD patients proteinuric (200 $\mathrm{mg}$ protein/g creatinine in spot urine) [42].

Diuretics are less commonly used in children with CKD than in adults with CKD, due to the preponderance of hypodysplastic kidney disorders, which frequently present as salt-losing nephropathies. In patients with evidence of hypervolemia, thiazides and loop diuretics have proven most useful for controlling volume overload, and they have a very good side-effects profile. It should be remembered that, while thiazides are a popular first-line therapy in mildto-moderate $\mathrm{CKD}$, they are less effective when glomerular filtration rate (GFR) falls below $60 \mathrm{ml} / \mathrm{min}$ per $1.73 \mathrm{~m}^{2}$ body surface area, and they are ineffective below $30 \mathrm{ml} / \mathrm{min}$ per $1.73 \mathrm{~m}^{2}$. Therefore, furosemide should be preferred and used in adequate doses for CKD stages 4 and 5. Mineralocorticoid receptor antagonists (e.g. spironolactone) are theoretically attractive in CKD, due to their synergistic actions with RAS antagonists, and the new selective receptor blocker eplerenone is devoid of anti-androgenic side effects. 
However, monotherapy (and, even more, combination therapy with RAS antagonists) is limited by the potentiated risk of hyperkalemia. During diuretic therapy, patients should be monitored for volume depletion and electrolyte disturbances. Long-acting formulations help to increase patient compliance [42].

Calcium channel blockers are very potent anti-hypertensive drugs and, therefore, useful as add-on therapy in children with resistant hypertension. Dihydropyridine (DHP) drugs (e.g. nifedipine, amlodipine) act mainly as vasodilators and do not have cardiac side effects. Amlodipine has pediatric labeling and is available as a suspension, and doses need not to be adjusted to renal function.

However, DHP-type calcium channel blockers (CCBs) increase intra-glomerular pressure and proteinuria, while non-DHP-type calcium channel blockers (e.g. verapamil and diltiazem) have an additional anti-proteinuric effect. In a long-term clinical trial of elderly patients with type II diabetic nephropathy, non-DHP calcium channel blockers showed as equally an effective slowing of CKD progression, reduction of proteinuria and antihypertensive efficacy as did the ACE inhibitor lisinopril (while both were superior to the beta blocker atenolol [73]). However, there are no published safety data on any of the non-DHPs in children with hypertension, so they should be used with caution due to their known prolongation of the PR interval in adults [74].

Intravenous administration of nicardipine is an option for controlling hypertensive crises, especially when the level of renal function is unclear or changing rapidly. It has been used safely, even in very small children with hypertension, despite reports of hypotension in normotensive newborns with asphyxia [74].

Beta blockers can be used as second-line therapy for renal hypertension in children. However, they are contraindicated in asthma and can cause fatigue. All beta blockers require dose reduction with progression of CKD. They should be used with caution in heart failure, and their adverse metabolic effects make them less suitable for diabetics. The largest clinical experience, especially for infants, is available for propranolol. A sustained-release form of this drug allows once daily administration in larger children. However, other agents, such as atenolol, which have the advantage of being both long acting and $\beta 1$ selective, may be preferred in clinical practice.

Other drugs are used less commonly, mainly due to their more severe side-effects profiles. Alpha blockers (such as prazosin) can be used in patients who also require them for control of bladder emptying or Raynaud's phenomenon. Centrally acting alpha agonists (such as clonidine) act via reduction of sympathetic nervous outflow. Rebound hypertension after discontinuation is a major problem of this drug. The vasodilators hydralazine and minoxidil are less suitable in CKD as they are less effective and cause salt and water retention.

The aim of antihypertensive management is the regression of end-organ damage (especially LVH) and the lowering of blood pressure below target values while minimizing drug side effects. The currently recommended treatment goal in hypertensive patients with CKD is a blood pressure of $<130 / 80 \mathrm{mmHg}$ in adults $[42,47]$ and $<90$ th percentile in children [46]. However, a meta-analysis of 11 randomized trials in non-diabetic adults with CKD showed differing results for proteinuric and non-proteinuric patients: while there was no increase in adverse renal outcomes with higher blood pressure in non-proteinuric patients, ideal systolic blood pressure for proteinuric patients ( $>1 \mathrm{~g}$ per day) was $110-129 \mathrm{mmHg}$. In proteinuric patients, renal survival decreased, with systolic blood pressures below $110 \mathrm{mmHg}$ and above $130 \mathrm{mmHg}$. These data are hard to interpret conclusively, as persistent hypertension during treatment may also be a reflection of more severe underlying disease [70]. In children, the pending results of the ESCAPE trial may help us to elucidate optimal blood pressure targets.

\section{Conclusion}

Adequate management of hypertension in CKD requires an active screening approach in order to prevent the significant renal deterioration and cardiovascular morbidity and mortality associated with high blood pressure. Owing to the plethora of different pathophysiological mechanisms involved, a whole range of therapeutic options is available. Non-pharmacological options should not be disregarded for obese children or for children on hemodialysis. Inhibitors of the renin-angiotensin system should be preferred for proteinuric patients and, probably, also for non-proteinuric patients. Multiple drug therapy is often necessary to reach target blood pressure below the 90th percentile. For this, diuretics and calcium channel blockers are the most suitable options.

\section{Questions}

(Answers appear after the reference list)

Indicate the correct answer (only one).

\section{Hypertension in CKD}

(a) is mainly a feature of the later stages of CKD.

(b) is caused by volume overload with normal total peripheral resistance.

(c) increases renal blood flow and, therefore, helps to maintain residual renal function. 
(d) can be caused by fluid overload, sympathetic nervous system hyperactivity and/or activation of the renin-angiotensin system.

2. In patients on hemodialysis with hypertension:

(a) serum sodium levels are not indicative of total body sodium load.

(b) reduction of fluid overload by intensified dialysis will swiftly lower blood pressure.

(c) low sodium dialysate causes intra-dialytic hypotensive symptoms and is therefore not advisable.

3. Adequate control of blood pressure

(a) is hard to achieve with monotherapy. Therefore fixed-dose combination therapy should be started as first-line therapy.

(b) is possible in a large number of hemodialysis patients on strict fluid management without antihypertensive drugs.

(c) can be assumed once a patient has normal clinic blood pressure values.

(d) makes screening for end-organ damage unnecessary.

4. Diuretics:

(a) thiazides should always be preferred to loop diuretics due to their longer duration of action.

(b) loop diuretics should always be preferred to thiazides due to their more potent diuretic action.

(c) diuretics can be dosed sparingly in CKD due to greater sensitivity of the nephrons.

(d) in a patient with a GFR of less than $30 \mathrm{ml} / \mathrm{min}$ per $1.73 \mathrm{~m}^{2}$ body surface area, thiazides should be preferred to loop diuretics.

(e) diuretics have additional antihypertensive efficacy if hypertension is still uncontrolled by reninangiotensin system blockade.

5. ACE inhibitors:

(a) retard progression of CKD only because they lower blood pressure.

(b) retard progression of CKD only because they reduce proteinuria.

(c) should not be used in proteinuric patients who already receive angiotensin receptor blockers.

(d) may cause hyperkalemia, increased serum creatinine, hypotension and cough but are generally well tolerated.

(e) should not be used in patients with polyuria, as they are mild diuretics.

6. Therapeutic life-style changes:

(a) renal hypertension is usually so pronounced that pharmacological treatment is needed, and burdening patients with therapeutic life-style changes is therefore unnecessary. (b) low salt diet is not necessary in obese children.

(c) there are no studies to show that weight loss, healthy diet, increased exercise or cessation of (passive) smoking are helpful in children with CKD.

7. Iatrogenic hypertension:

(a) erythropoietin (EPO)-induced hypertension is mainly due to the increase in hematocrit.

(b) calcium channel blockers may be a specific therapy for EPO-induced hypertension.

(c) beta blockers may be a specific therapy for EPOinduced hypertension.

(d) growth hormone causes salt and water retention with clinically relevant hypertension in children with ESRD.

(e) cyclosporine A causes hypertension via constriction of the efferent glomerular arteriole.

8. The target blood pressure in pharmacological treatment is:

(a) the 95th age- and height-dependent percentile in all children with CKD.

(b) the 50th percentile in children with CKD stage 4 and above.

(c) independent of co-morbid diseases.

(d) still being debated but at least the 90th percentile in children with end-organ damage or CKD.

\section{References}

1. Wong H, Mylera K, Feber J, Drukker A, Filler G (2006) Prevalence of complications in children with chronic kidney disease according to KDOQI. Kidney Int 70:585-590

2. Wingen AM, Fabian-Bach C, Schaefer F, Mehls O, European Study Group for Nutritional Treatment of Chronic Renal Failure in Childhood (1997) Randomised multicentre study of a lowprotein diet on the progression of chronic renal failure in children. Lancet 349:1117-1123

3. Mitsnefes MM, Ho PL, McEnery PT (2003) Hypertension and progression of chronic renal insufficiency in children: a report of the North American Pediatric Renal Transplant Cooperative Study (NAPRTCS). J Am Soc Nephrol 14:2618-2622

4. Groothoff JW, Gruppen MP, Offringa M, Hutten J, Lilien MR, Van De Kar NJ, Wolff ED, Davin JC, Heymans HS (2002) Mortality and cause of death of end-stage renal disease in children: a Dutch cohort study. Kidney Int 61:621-629

5. Tkaczyk M, Nowicki M, Balasz-Chmielewska I, BoguszewskaBaczkowska H, Drozdz D, Kollataj B, Jarmolinski T, Jobs K, Killis-Pstrusinska K, Leszczynska B, Makulska I, Runowski D, Stankiewicz R, Szczepanska M, Wiercinski R, Grenda R, Kanik A, Pietrzyk JA, Roszkowska-Blaim M, Szprynger K, Zachwieja J, Zajaczkowska MM, Zoch-Zwierz W, Zwolinska D, Zurowska A (2006) Hypertension in dialysed children: the prevalence and therapeutic approach in Poland - a nationwide survey. Nephrol Dial Transplant 21:736-742

6. Brass H, Ochs HG, Armbruster H, Heintz R (1976) Plasma renin activity (PRA) and aldosterone (PA) in patients with chronic glomerulonephritis (GN) and hypertension. Clin Nephrol 5:57-60 
7. Warren DJ, Ferris TF (1970) Renin secretion in renal hypertension. Lancet 1:159-162

8. Loghman-Adham M, Soto CE, Inagami T, Cassis L (2004) The intrarenal renin-angiotensin system in autosomal dominant polycystic kidney disease. Am J Physiol Renal Physiol 287:F775-F788

9. Ibrahim HN, Hostetter TH (1998) The renin-aldosterone axis in two models of reduced renal mass in the rat. J Am Soc Nephrol 9:72-76

10. Wolf G, Butzmann U, Wenzel UO (2003) The renin-angiotensin system and progression of renal disease: from hemodynamics to cell biology. Nephron Physiol 93:P3-P13

11. Sorof JM, Brewer ED, Portmann RJ (1999) Ambulatory blood pressure monitoring and interdialytic weight gain in children receiving chronic hemodialysis. Am J Kidney Dis 33:667-674

12. Charra B, Bergström J, Scribner BH (1998) Blood pressure control in dialysis patients: importance of the lag phenomenon. Am J Kidney Dis 32:720-724

13. Klein IH, Ligtenberg G, Oey PL, Koomans HA, Blankestijn PJ (2001) Sympathetic activity is increased in polycystic kidney disease and is associated with hypertension. J Am Soc Nephrol $12: 2427-2433$

14. Weidmann P (1984) Pathogenesis of hypertension associated with chronic renal failure. Contrib Nephrol 41:47-65

15. Ye S, Ozgur B, Campese VM (1997) Renal afferent impulses, the posterior hypothalamus, and hypertension in rats with chronic renal failure. Kidney Int 51:722-727

16. Ligtenberg G, Blankenstijn PJ, Oey PL, Klein IH, Dijkhorst-Oei LT, Boomsma F, Wieneke GH, van Huffelen AC, Koomans HA (1999) Reduction of sympathetic hyperactivity by enalapril in patients with chronic renal failure. N Engl J Med 340:1321-1328

17. Kuchel OG, Shigetomi S (1994) Dopaminergic abnormalities in hypertension associated with moderate renal insufficiency. Hypertension 23:I240-I245

18. Wolf G, Chen S, Han DC, Ziyadeh FN (2002) Leptin and renal disease. Am J Kidney Dis 39:1-11

19. Tory K, Horváth E, Süveges Z, Fekete A, Sallay P, Berta K, Szabó T, Szabó AJ, Tulassay T, Reusz GS (2004) Effect of propranolol on heart rate variability in patients with end-stage renal disease: a double-blind, placebo controlled, randomized crossover pilot trial. Clin Nephrol 61:316-323

20. Miyajima E, Yamada Y, Yoshida Y, Matsukawa T, Shionoiri H, Tochikubo O, Ishii M (1991) Muscle sympathetic nerve activity in renovascular hypertension and primary aldosteronism. Hypertension 17:1057-1062

21. Faber JE, Brody MA (1985) Afferent renal nerve-dependent hypertension following acute renal artery stenosis in the conscious rat. Circ Res 57:676-688

22. Rauh W, Hund E, Sohl G, Rascher W, Mehls O, Schärer K (1983) Vasoactive hormones in children with chronic renal failure. Kidney Int Suppl 15:S27-S33

23. Xu J, Li G, Wang P, Velazquez H, Yao X, Li Y, Wu Y, Peixoto A, Crowley S, Desir GV (2005) Renalase is a novel, soluble monoamine oxidase that regulates cardiac function and blood pressure. J Clin Invest 115:1275-1280

24. Boomsma F, Tipton KF (2007) Renalase, a catecholaminemetabolising enzyme? J Neural Transm 114:775-776

25. Matsuguma K, Ueda S, Yamagishi S, Matsumoto Y, Kaneyuki U, Shibata R, Fujimura T, Matsuoka H, Kimoto M, Kato S, Imaizumi T, Okuda S (2006) Molecular mechanism for elevation of asymmetric dimethylarginine and its role for hypertension in chronic kidney disease. J Am Soc Nephrol 17:2176-2183

26. Zoccali C, Bode-Böger S, Mallamaci F, Benedetto F, Tripepi G, Malatino L, Cataliotto A, Bellanuova I, Fermo I, Frölich J, Böger R (2001) Plasma concentration of asymmetrical dimethylarginine and mortality in patients with end-stage renal disease: a prospective study. Lancet 358:2113-2117
27. Fliser D, Kronenberg F, Kielstein JT, Morath C, Bode-Böger SM, Haller H, Ritz E (2005) Asymmetric dimethylarginine and progression of chronic kidney disease: the mild to moderate kidney disease study. J Am Soc Nephrol 16:2254-2256

28. Vaziri ND, Ni X, Wang Q, Oveisi F, Zhou XJ (1998) Downregulation of nitric oxide synthase in chronic renal insufficiency: role of excess PTH. Am J Physiol Renal Physiol 274:F642-F649

29. Raine AE, Bedford L, Simpson AW, Ashley CC, Brown R, Woodhead JS, Ledingham JG (1993) Hyperparathyroidism, platelet intracellular free calcium and hypertension in chronic renal failure. Kidney Int 43:700-705

30. Iseki K, Massry SG, Campese VM (1986) Effects of hypercalcemia and parathyroid hormone on blood pressure in normal and renal failure rats. Am J Physiol 250:924-929

31. Schiffl H, Fricke H, Sitter T (1993) Hypertension secondary to early-stage kidney disease: the pathogenetic role of altered cytosolic calcium $(\mathrm{Ca} 2+)$ homeostasis of vascular smooth muscle cells. Am J Kidney Dis 21:51-57

32. Carlini RG, Reyes AA, Rothstein M (1995) Recombinant human erythropoietin stimulates angiogenesis in vitro. Kidney Int 47:740-745

33. Vaziri ND (1999) Mechanism of erythropoietin-induced hypertension. Am J Kidney Dis 33:821-828

34. Ni Z, Wang XQ, Vaziri ND (1988) Nitric oxide metabolism in erythropoietin-induced hypertension: effect of calcium channel blockade. Hypertension 32:724-729

35. Busauschina A, Schnuelle P, van der Woude FJ (2004) Cyclosporine nephrotoxicity. Transplant Proc 36:229S-233S

36. Esteva-Font C, Ars E, Guillen-Gomez E, Campistol JM, Sanz L, Jiménez W, Knepper MA, Torres F, Torra R, Ballarin JA, Fernández-Llama P (2007) Cyclosporine-induced hypertension is associated with increased sodium transporter of the loop of Henle (NKCC2). Nephrol Dial Transplant 22:2810-2816

37. Neu AM, Ho PL, Fine RN, Furth SL, Fivush BA (2003) Tacrolimus vs cyclosporine A as primary immunosuppression in pediatric renal transplantation: a NAPRTCS study. Pediatr Transplant 7:217-222

38. Sinha MD, MacLeod R, Rigby E, Clark AG (2006) Treatment of severe steroid-dependent nephrotic syndrome (SDNS) in children with tacrolimus. Nephrol Dial Transplant 21:1761-1763

39. Johannson G, Sverrisdóttir YB, Ellegard L, Lundberg PA, Herlitz H (2002) GH increases extracellular volume by stimulating sodium reabsorption in the distal nephron and preventing pressure natriuresis. J Clin Endocrinol Metab 87:1743-1749

40. Tönshoff B, Heinrich U, Mehls O (1991) How safe is the treatment of uraemic children with recombinant human growth hormone? Pediatr Nephrol 5:454-460

41. Nathwani D, Unwin R, Brook CG, Hindmarsh PC (2002) The influence of renal and cardiovascular abnormalities on blood pressure in Turner syndrome. Clin Endocrinol (Oxf) 52:371-377

42. Kidney Disease Outcomes Quality Initiative (K/DOQI) Group (2004) K/DOQI clinical practice guidelines on hypertension and antihypertensive agents in chronic kidney disease. Am J Kidney Dis 43:S1-S290

43. Mitsnefes M, Stablein D (2005) Hypertension in pediatric patients on long-term dialysis: a report of the North American Pediatric Renal Transplant Cooperative Study (NAPRTCS). Am J Kidney Dis 45:309-315

44. Wühl E, Hadtstein C, Mehls O, Schaefer F, ESCAPE trial group (2004) Home, clinic, and ambulatory blood pressure monitoring in children with chronic renal failure. Pediatr Res 55:492-497

45. Lurbe E, Torro I, Alvarez V, Nawrot T, Paya R, Redon J, Staessen J (2005) Prevalence, persistence and clinical significance of masked hypertension in youth. Hypertension 45:493-398

46. National High Blood Pressure Education Program Working Group on High Blood Pressure in Children and Adolescents (2004) The 
fourth report on the diagnosis, evaluation, and treatment of high blood pressure in children and adolescents. Pediatrics 114:555-576

47. Chobanian AV, Barkis GL, Black DL, Cushman WC, Green LA, Izzo JL Jr, Jones DW, Materson BJ, Oparil S, Wright JT Jr, Roccella EJ (2003) The Seventh Report of the Joint National Committee on Prevention, Detection, Evaluation, and Treatment of High Blood Pressure. JAMA 289:2560-2571

48. Wühl E, Witte K, Soergel M, Mehls O, Schaefer F, German Working Group on Pediatric Hypertension (2002) Distribution of 24-h ambulatory blood pressure in children: normalized reference values and role of body dimensions. J Hypertens 20:19952007

49. Stergiou GS, Yiannes NG, Rarra VC, Panagiotakos DB (2007) Home blood pressure normalcy in children and adolescents: the Arsakeion school study. J Hypertens 25:1375-1379

50. Matteucci MC, Wühl E, Picca S, Mastrostefano A, Rinelli G, Romano C, Rizzoni G, Mehls O, de Simone G, Schaefer F (2006) Left ventricular geometry in children with mild to moderate chronic renal insufficiency. J Am Soc Nephrol 17:218-226

51. Litwin M, Wühl E, Jourdan C, Trelewicz J, Niemirska A, Fahr K, Jobs K, Grenda R, Wawer ZT, Rajszys P, Tröger J, Mehls O, Schaefer F (2005) Altered morphologic properties of large arteries in children with chronic renal failure and after renal transplantation. J Am Soc Nephrol 16:1494-1500

52. Jourdan C, Wühl E, Litwin M, Fahr K, Trelewicz J, Jobs K, Schenk J, Grenda R, Mehls O, Tröger J, Schaefer F (2005) Normative values for intima-media thickness and distensibility of large arteries in healthy adolescents. J Hypertens 23:1707-1715

53. Hörl MP, Hörl WH (2002) Hemodialysis-associated hypertension: pathophysiology and therapy. Am J Kidney Dis 39:227-244

54. Ozkahya M, Toz H, Unsal A, Ozerkan F, Asci G, Gurgun C, Akcicek F, Mees FJ (1999) Treatment of hypertension in dialysis patients by ultrafiltration: role of cardiac dilatation and time factor. Am J Kidney Dis 34:218-222

55. Thein H, Haloob I, Marshall MR (2007) Associations of a facility level decrease in dialysate sodium concentration with blood pressure and interdialytic weight gain. Nephrol Dial Transplant 22:2630-2639

56. Krautzig S, Janssen U, Koch KM, Granolleras C, Shaldon S (1998) Dietary salt restriction and reduction of dialysate sodium to control hypertension in maintenance haemodialysis patients. Nephrol Dial Transplant 13:552-553

57. Figueroa-Colon R, Franklin FA, Lee JY, von Almen TK, Suskind RM (1996) Feasibility of a clinic-based hypocaloric dietary intervention implemented in a school setting for obese children. Obes Res 4:419-429

58. Rocchini AP, Key J, Bondie D, Chico R, Moorehead C, Katch V, Martin M (1989) The effect of weight loss on the sensitivity of blood pressure to sodium in obese adolescents. N Engl J Med 321:580-585

59. The GISEN Group (Gruppo Italiano di Studi Epidemiologici in Nefrologia) (1997) Randomised placebo-controlled trial of effect of ramipril on decline in glomerular filtration rate and risk of terminal renal failure in proteinuric, non-diabetic nephropathy. Lancet 349:1857-1863

60. Bianchetti MG, Ammenti A, Avolio L, Bettinelli A, Bosio M, Fossali E, la Manna A, Maringhini S, Pela I, Ratsch IM, Viganò S, Ardissino G, Italkid Project, CHIld Project (2007) Prescription of drugs blocking the renin-angiotensin system in Italian children. Pediatr Nephrol 22:144-148

61. Woroniecki RP, Flynn JT (2005) How are hypertensive children evaluated and managed? A survey of North American pediatric nephrologists. Pediatr Nephrol 20:791-797

62. Wühl E, Mehls O, Schaefer F, ESCAPE trial group (2004) Antihypertensive and antiproteinuric efficacy of ramipril in children with chronic renal failure. Kidney Int 66:768-776
63. Nakao N, Yoshimura A, Morita H, Takada M, Kayano T, Ideura T (2003) Combination treatment of angiotensin-II receptor blocker and angiotensin-converting-enzyme inhibitor in non-diabetic renal disease (COOPERATE): a randomised controlled trial. Lancet 361:117-124

64. Campbell R, Sangalli F, Perticucci E, Aros C, Viscarra C, Perna A, Remuzzi A, Bertocchi F, Fagiani L, Remuzzi G, Ruggenenti P (2003) Effects of combined ACE inhibitor and angiotensin II antagonist treatment in human chronic nephropathies. Kidney Int 63:1094-1103

65. Tanaka H, Suzuki K, Nakahata T, Tsugawa K, Konno Y, Tsuruga $\mathrm{K}$, Ito E, Waga S (2004) Combined therapy of enalapril and losartan attenuates histologic progression in immunoglobulin $\mathrm{A}$ nephropathy. Pediatr Int 46:576-579

66. Yang Y, Ohta K, Shimizu M, Nakai A, Kasahara Y, Yachie A, Koizumi S (2005) Treatment with low-dose angiotensin-converting enzyme inhibitor (ACEI) plus angiotensin II receptor blocker (ARB) in pediatric patients with IgA nephropathy. Clin Nephrol 64:35-40

67. Lubrano R, Soscia F, Elli M, Ventrigilia F, Raggi C, Travasso E, Scateni S, Di Maio V, Versacci P, Masciangelo R, Romero S (2006) Renal and cardiovascular effects of angiotensin-converting enzyme inhibitor plus angiotensin II receptor antagonist therapy in children with proteinuria. Pediatrics 118:e833-e838

68. Litwin M, Grenda R, Sladowska J, Antoniewicz J (2006) Add-on therapy with angiotensin II receptor 1 blocker in children with chronic kidney disease already treated with angiotensin-converting enzyme inhibitors. Pediatr Nephrol 21:1716-1722

69. Hanevold CD (2006) Acute renal failure during lisinopril and losartan therapy for proteinuria. Pharmacotherapy 26:1348-1351

70. Jafar TH, Stark PC, Schmid CH, Landa M, Maschio G, de Jong PE, de Zeeuw D, Shahinfar S, Toto R, Levey AS, AIPRD study group (2003) Progression of chronic kidney disease: the role of blood pressure control, proteinuria, and angiotensin-converting enzyme inhibition: a patient-meta-analysis. Ann Intern Med 139:244-252

71. Jafar TH, Schmid CH, Landa M, Giatras J, Toto R, Remuzzi G, Maschio G, Brenner BM, Kamper A, Zucchelli P, Becker G, Himmelmann A, Bannister K, Landais P, Shahinfar S, DeJong P, DeZeeuw D, Lau J, Levey AS, ACE Inhibition in Progressive Renal Disease Study Group (2001) Angiotensin-converting enzyme inhibitors and progression of nondiabetic renal disease. A metaanalysis of patient-level data. Ann Intern Med 135:73-87

72. Douglas JG, Agoda L (2003) ACE inhibition is effective and renoprotective in hypertensive nephrosclerosis: the African American study of kidney disease and hypertension (AASK) trial. Kidney Int Suppl 83:S74-S76

73. Bakris GL, Copley JB, Vicknair N, Sadler R, Leurgans S (1996) Calcium channel blockers vs other antihypertensive therapies on progression of NIDDM associated nephropathy. Kidney Int 50:1641-1650

74. Sahney S (2006) A review of calcium channel antagonists in the treatment of pediatric hypertension. Paediatr Drugs 8:357-373

\section{Answers}

1. (d)

2. (a)

3. (b)

4. (e)

5. (d)

6. (c)

7. (b)

8. (d) 